\title{
Safety of Albumin and Hydroxyethyl Starch as Priming Fluid for Cardiopulmonary Bypass in Cardiac Surgery: A Meta-analysis of Randomized Controlled Trials
}

\section{Mingtang Ye}

Children's Hospital of nanjing medical university

\section{Xiaodong Zang}

Children's Hospital of nanjing medical university

\section{Peicheng Ding}

Children's Hospital of nanjing medical university

\section{Ruonan Wang}

Children's Hospital of nanjing medical university

\section{Feng Chen}

Children's Hospital of nanjing medical university

Jirong Qi

Children's Hospital of nanjing medical university

\section{Zhaocong Yang}

Children's Hospital of nanjing medical university

\section{Xuming Mo ( $\nabla$ mohsuming15@njmu.edu.cn )}

Children's Hospital of nanjing medical university

\section{Research article}

Keywords: albumin, hydroxyethyl starch, cardiopulmonary bypass, priming fluid

Posted Date: November 10th, 2020

DOI: https://doi.org/10.21203/rs.3.rs-102683/v1

License: (c) (i) This work is licensed under a Creative Commons Attribution 4.0 International License. Read Full License 


\section{Abstract}

Introduction: Hydroxyethyl starch (HES) has been widely used for volume expansion, but its safety as priming fluid for cardiopulmonary bypass has been questioned recently. The aim of this meta-analysis is to compare the safety of albumin and hydroxyethyl starch as priming fluid for cardiopulmonary bypass.

Methods: Pubmed, Embase database and Cochrane Library were searched for randomized controlled trials (RCTs) involving patients who received HES or albumin as priming fluid for cardiopulmonary bypass in cardiac surgery published up to October 2019. Two reviewers independently extracted the valid data, including the length of ICU stay, ventilator time, the length of hospital stay, crystal volume, fresh frozen plasma, platelet input, blood loss, blood platelet count. hemoglobin value, fibrin, APTT, PT, urea, creatinine and urine volume. Meta-analysis was performed with revman version 5.3.

Results: Total 9 RCTs involving 452 patients were included in this meta-analysis. Compared with albumin, HES had similar effects on the length of ICU stay $\left(M D=0.70 \otimes 95 \% \mathrm{CI}-0.14\right.$ to $1.55 \otimes P=0.10 \otimes I^{2}=$ $89 \%)$;ventilation time( $\mathrm{MD}=2.31 ; 95 \% \mathrm{Cl}-3.93$ to $\left.8.55 ; \mathrm{P}=0.47, \mathrm{I}^{2}=60 \%\right)$; the length of hospital stay $(\mathrm{MD}=$ $-0.31 ; 95 \%$ Cl:-2.00 to $1.37 ; \mathrm{P}=0.71 ; \mathrm{l}^{2}=0 \%$; crystal volume(SMD $=0.26 ; 95 \% \mathrm{Cl}:-0.09$ to $0.61 ; \mathrm{P}=0.15 ; \mathrm{I}^{2}=$

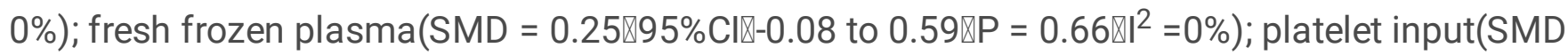
$=-0.17 ; 95 \% \mathrm{Cl}:-0.59$ to $0.26 ; \mathrm{P}=0.45 ; \mathrm{I}^{2}=0 \%$ ); blood loss (SMD $=0.31 ; 95 \% \mathrm{Cl}:-0.01$ to $0.63 ; \mathrm{P}=0.06 ; \mathrm{I}^{2}$ $=29 \%)$;platelet count $\left(\mathrm{SMD}=-0.21 ; 95 \% \mathrm{cl}:-0.54\right.$ to $\left.0.11 ; \mathrm{P}=0.20 ; 1^{2}=29 \%\right)$;hemoglobin value(SMD $=0.1 ; 95 \% \mathrm{Cl}:-0.15$ to $\left.0.36 ; \mathrm{P}=0.42 ; \mathrm{I}^{2}=0 \%\right)$; fibrin (SMD $=0.12 ; 95 \% \mathrm{Cl}:-0.19$ to $0.44 ; \mathrm{P}=0.45 ; \mathrm{I}^{2}=0 \%$ );APTT(MD =1.13;95\% Cl: -2.06 to $\left.4.32 ; \mathrm{P}=0.49 ; \mathrm{I}^{2}=0 \%\right) ; \mathrm{PT}\left(\mathrm{MD}=0.10 ; 95 \% \mathrm{Cl}:-0.21\right.$ to $0.40, \mathrm{P}=0.52 ; \mathrm{I}^{2}=$ $0 \%)$;creatinine(SMD $=0.09 ; 95 \% \mathrm{Cl}:-0.32$ to $0.50 ; \mathrm{P}=0.66 ; \mathrm{I}^{2}=51 \%$ ); urine volume(SMD $=0.11 ; 95 \% \mathrm{Cl}$ : -0.26 to $\left.0.48 ; P=0.55 ; I^{2}=43 \%\right)$.but did not increase urea (SMD $=-0.46 ; 95 \% \mathrm{Cl}:-0.81$ to $-0.11 ; P=0.01 ; I^{2}$ $=0 \%$.

Conclusions: HES was safe and effective compared to albumin as priming fluid for cardiopulmonary bypass because it did not affect renal function, coagulation function, liquid input, or the length of ICU stay and ventilation time of patients.

\section{Introduction}

Currently, cardiopulmonary bypass (CPB) is an important adjunct to cardiac surgery because it improves the success of cardiac surgery. By providing low blood flow perfusion, CPB prolongs the safe operation time and provides basic blood flow supply for various organs of the human body. However, CPB can lead to blood dilution, decrease plasma osmotic pressure, damage vascular endothelial cells (VEC), increase vascular permeability, and cause systemic complications such as postoperative tissue edema, cardiac insufficiency, pulmonary exudation,infection, liver and renal insufficiency ${ }^{[1]}$. At present, how to select priming fluid for CPB is a focus of controversy. 
CPB priming solution directly affects the change of colloid pressure and the incidence of VEC damage after cardiac operation. Albumin has become the preferred fluid for patients undergoing CPB in many centers. Compared with other liquids, albumin is a natural colloid that effectively provides plasma colloid osmotic pressure ${ }^{[2]}$, protects vascular endothelium, delays fibrinogen adhesion in circulation pipeline, and reduces surface activation and platelet adhesion ${ }^{[3]}$. Large randomized controlled trials comparing albumin with other fluids have not been conducted in patients undergoing cardiac surgery. Engelman et al. ${ }^{[4]}$ reported that preoperative hypoalbuminemia (<25 g.L-1) is an independent risk factor for various adverse outcomes after cardiac surgery. Fritz et al. ${ }^{[5]}$ found that hypoalbuminemia was even better than EuroSCORE score in predicting mortality after cardiac surgery, and the cut-off point for hypoalbuminemia was $18 \mathrm{~g} \cdot \mathrm{L}-1$. Several other studies have evaluated the effectiveness of albumin as priming fluid for CPB. A retrospective cohort study by Sedrakyan et al. ${ }^{[6]}$ enrolled 19,578 CABG patients, the results showed that compared with the older generation of artificial colloid, albumin was associated with a reduction in mortality ( $\mathrm{OR}=0.8,95 \% \mathrm{Cl}: 0.67$ to 0.96$)$, and compared to crystal liquids, the albumin group required less priming fluid. In addition, the use of albumin as priming fluid can reduce postoperative blood loss.

Onorati et al. ${ }^{[7]}$ retrospectively compared low dose albumin with pure crystal as priming fluid solution in 377 patients, and patients who received albumin need less blood transfusion and had less blood loss after surgery.

Hydroxyethyl Starch (HES) is another plasma substitute widely used in the clinic practice since 1960s, which is made of high molecular weight amylopectin through degradation, hydroxyethylation and further processing. HES is mainly used to prevent or treat intraoperative hypotension and hemodilution ${ }^{[8,9]}$. On June 14, 2013, due to safety concerns, the European Medicines Agency (EMA) and Drug Risk Assessment Committee (PRAC) recommended the delisting of HES. At the end of June 2013, U.S. officials pointed out that HES may increase the death rate of patients, cause the decline of hemostatic function of patients [10] and have serious negative effects on the kidneys ${ }^{[11]}$, and issued a warning to HES ${ }^{[12]}$. A meta-analysis by Myburgh et al. ${ }^{[13]}$ showed that HES can increase the amount of blood transfusion during reoperation due to bleeding. These negative effects are not directly related to the average molecular weight and substitution level of HES. However, a recent study showed that the use of artificial colloid as priming fluid for $\mathrm{CPB}$ has not raised the risk of organ injury ${ }^{[14]}$. Moreover, many randomized controlled clinical studies showed that for patients undergoing cardiac surgery with normal organ function and coagulation function, the use of artificial colloid as priming fluid for CPB has not raised the risk of organ injury. At present, artificial colloidal fluids are still widely used for priming fluid of $C P B$, but there is no definite clinical evidence to support the safety or even superiority of artificial colloid priming fluid of CPB. Therefore, we performed this meta-analysis to compare the safety of albumin and HES as priming fluid for CPB to provide reference for clinical application.

\section{Materials And Methods}

\section{1 inclusion criteria and exclusion criteria}


1.1.1 Included in the study: The types of literature included in the study are randomized controlled trial (RCT) regardless of whether blind method and allocation concealment are used. The language is limited to English.

1.1.2 The inclusion criteria were: (1) RCTs;(2) The subjects of the study were heart disease patients;(3) HES was used in the test group and albumin was used in the control group.(4) All were extracorporeal circulation operations.

1.1.3 The exclusion criteria were: (1) Summary, review, case report, clinical observation and unpublished data;(2) No statistical;(3) Repeated detection or repeated published research;(4) No mention of research type;(5) Unable to obtain full text;(6)Coagulopathy;(7)Anemia; (8)Hepatic dysfunction, (9)Reoperation.

1.1.4 Interventions: The colloidal liquid in the experimental group was HES. The colloidal solution in the control group was human serum albumin.

1.1.5 Outcome indicators included: the length of ICU stay, ventilator time, the length of hospital stay, crystal volume, fresh frozen plasma, platelet input, blood loss, blood platelet count. hemoglobin value, fibrin, APTT, PT, urea, creatinine and urine volume.

\subsection{Search strategies}

PubMed, Embase and the Cochrane Library were searched using the following key words and related free words: 'cardiopulmonary bypass', 'albumin', 'Hydroxyethyl Starch'. The relevant clinical trials were those published before October 2019 that met the above criteria. The search was limited to 'randomized controlled trials', 'human', and the language was restricted to English.

\subsection{Study selection and data extraction}

Two reviewers (Ye and Zang) independently screened the search results and obtained the full texts according to the inclusion and exclusion criteria, and independently extracted the valid data. Data extraction and analysis were performed under the supervision of an experienced statistician (Mo).

\subsection{Quality assessment}

Risk of bias assessment was performed using the'Risk of bias' tool in the Cochrane Handbook for Systematic Reviews of Interventions ${ }^{[15]}$. We assessed each study according to the quality domains of random sequence generation, allocation concealment, blinding of participants and personnel, incomplete outcome data, selective outcome reporting and other bias.

\section{5 statistical analysis}

Data were analyzed by Review Manager (5.3 RevMan, Cochrane Collaboration). The continuous effect data were assessed by mean difference (MD). When median and extreme values were presented in the original articles, these data were converted into mean and standard deviation according to relevant 
formulas ${ }^{[16]}$. Non-continuous data were assessed by the risk ratio (RR). Statistical heterogeneity of the data was analyzed quantitatively by the $\left.\right|^{2}$-test ${ }^{[17]}$. The decision of to use fixed effect or random effect is based on whether we believe that the true effect is the same in all studies, i.e. all of the studies are identical and the true effect size is the same across all studies. If this is believed to be true (which is a very strong assumption, rarely found), then fixed effect should be used; if not, random effect should be used instead. Publication bias was tested by funnel plots. Two-sided tests were performed with a significant difference defined at $\mathrm{P}<0.05$.

\section{Results}

\subsection{Literature search and study selection}

Figure 1 showed the flow chart of the literature search, and we identified total 665 articles, from which 452 were excluded after reading the titles, abstracts and full texts. Finally, 9 RCTs were included in this meta-analysis.囚Figure1》

\subsection{The characteristics of the 9 RCTs}

The 9 RCTs included 452 patients treated with CPB. The characteristics of intervention measures, outcome indicators, and number of participants of 9 RCTs were shown in Table1.

Table 1. Characteristics of the included RCTs.

\begin{tabular}{|c|c|c|c|c|c|c|c|c|c|}
\hline Author & $\begin{array}{l}\text { Sof } \\
\text { male }\end{array}$ & Location & Age $(\mathrm{M})$ & \multirow{2}{*}{\multicolumn{2}{|c|}{$\begin{array}{c}\begin{array}{c}\text { Sample } \\
\text { Size }\end{array} \\
\text { HES HA }\end{array}$}} & $\begin{array}{l}\text { Follow-up } \\
\text { time }\end{array}$ & Type of heart disease & Intervention & Outcome assessment \\
\hline & & & & & & & & & \\
\hline Miao 2014 & 38 & China & $0.67 \pm 0.23$ & 30 & 30 & $\begin{array}{l}6 \text { hours after } \\
\text { surgery }\end{array}$ & $\mathrm{CHD}$ & $\begin{array}{c}\text { 6W HES } 130 / 0.4 \text { or } 3.36 \\
\text { albumin }\end{array}$ & $\begin{array}{l}\text { the length of ICU stay, ventilator } \\
\text { time, crystal volume, fresh frozen } \\
\text { plasma, urine volume }\end{array}$ \\
\hline patel 2016 & 64 & India & $1.33 \pm 1.13$ & 35 & 35 & $\begin{array}{l}24 \text { hours } \\
\text { after surgery }\end{array}$ & $\mathrm{CHD}$ & albumin or HES130/0.4 & $\begin{array}{c}\text { urine volume, ventilator time, the } \\
\text { length of ICU stay,blood platelet } \\
\text { count. hemoglobin value, ures. } \\
\text { creatinine }\end{array}$ \\
\hline saunders 1983 & & America & $60.7 \pm 9.24$ & 10 & 10 & After Bypass & aortocoronary bypass & HES or $25 \%$ albumin & urine volume, fibrinogen \\
\hline Philippe2013 & 52 & America & $5.2 \pm 7.40$ & 31 & 30 & $\begin{array}{l}\text { After arrival } \\
\text { on ICU until } \\
\text { first } \\
\text { postoperativ } \\
\text { e morning }\end{array}$ & $\mathrm{CHD}$ & $\begin{array}{l}\text { 6\% HES } 130 \mathrm{~V} 0.4 \text { or } 5 \% \\
\text { human albumin }\end{array}$ & $\begin{array}{c}\text { fresh frozen plasma, Platelet input, } \\
\text { amount of bleoding. fibrinogen, } \\
\text { APTT, hemoglobin value, urea, } \\
\text { creatinine }\end{array}$ \\
\hline Kuitunen 2004 & 90 & Finland & $60 \pm 20$ & 15 & 15 & $\begin{array}{c}2 \text { hours after } \\
\text { surgery }\end{array}$ & aortocoronary bypass & $\begin{array}{l}\text { HES } 120 \text {, molecular } \\
\text { woight } \\
120,000 \text { daltons or } 44 \\
\text { human }\end{array}$ & $\begin{array}{l}\text { the length of ICU stay, the length of } \\
\text { hospital stay. crystal volume. } \\
\text { amount of bleeding. blood platelet } \\
\text { count, hemoglobin value, urine }\end{array}$ \\
\hline Cho 2014 & 63 & Korea & $60.5 \pm 15.33$ & 18 & 18 & $\begin{array}{l}24 \text { hours } \\
\text { after surgery }\end{array}$ & $\begin{array}{l}\text { complex valvular } \\
\text { heart disease }\end{array}$ & $\begin{array}{l}\text { 6.6 hydroxyethyl starch } \\
\text { (HES) } 130 / 0.4 \text { or albumin }\end{array}$ & $\begin{array}{l}\text { the length of ICU stay, the length of } \\
\text { hospital stay. amount of bleeding. } \\
\text { blood platelet count. APTT. PT }\end{array}$ \\
\hline Palanzo 1982 & & America & $57.6 \pm 8.59$ & 37 & 42 & $\begin{array}{l}24 \text { hours } \\
\text { after surgery }\end{array}$ & $\begin{array}{l}\text { patients under- } \\
\text { going myocardial } \\
\text { revascularization }\end{array}$ & $\begin{array}{l}\text { 25* album ior } 6 \% \\
\text { hetastarchn }\end{array}$ & $\begin{array}{l}\text { fresh frozen plasma, Platelet input, } \\
\text { blood platelet count, fibrinogen, } \\
\text { APTT. PT. hemoglobin value }\end{array}$ \\
\hline Mahnood 2015 & 63 & Iran & $63.96 \pm 9.13$ & 30 & 30 & $\begin{array}{l}24 \text { hours } \\
\text { after surgery }\end{array}$ & aortocoronary bypass & $\begin{array}{c}\text { 5\% Albumin or } 6 \% \\
\text { Hydroxyethyl Starch } \\
130 / 0.4\end{array}$ & amount of bleeding, creatinine \\
\hline Chol 2010 & 30 & Korea & $54.5 \pm 12.86$ & 18 & 18 & $\begin{array}{l}24 \text { hours } \\
\text { after surgery }\end{array}$ & $\begin{array}{l}\text { patients undergoing } \\
\text { mitral valvular heart } \\
\text { surgery }\end{array}$ & $\begin{array}{l}\text { 5W Albumin or 6\% } \\
\text { Hydroxyethyl Starch } \\
13000.4\end{array}$ & $\begin{array}{l}\text { urine volume, crystal volume. } \\
\text { amount of bleeding. blood platelet } \\
\text { count. APTI. PT, hemoglobin valur }\end{array}$ \\
\hline
\end{tabular}

According to Cochrane's systematic evaluation manual, the methodological quality of the 9 clinical studies included in the study was evaluated for items such as random method, allocation concealment, blind method, withdrawal from missed visits and selective reporting $\triangle$ Figure 2). 


\subsection{Results of meta-analysis}

2.3.1 The length of ICU stay. Four RCTs reported the length of ICU stay. There was no statistical heterogeneity among the studies $\left(P=0.10 \otimes 1^{2}=89 \%\right)$, and the random effect model was selected for the analysis. The results showed no significant difference in the length of ICU stay between the HES group and the albumin group $\triangle \mathrm{MD}=0.70 \otimes 95 \% \mathrm{CI} \bigotimes-0.14$ to $1.55 \rrbracket \mathrm{P}=0.10 \otimes$ (Figure $3 \mathrm{~A}$ ). Therefore, the use of albumin and HES as priming fluid for CPB in cardiac surgery had a similar effect on the length of stay in ICU. (Figure 3A).

2.3.2 Ventilation time. Two RCTs reported the ventilation time. There was no statistical heterogeneity among the studies $\left(P=0.12 \varangle \mathrm{I}^{2}=60 \%\right)$, and the random effect model was selected for analysis. The results showed no significant difference between the HES group and the albumin group (MD = 2.31 $; 95 \% \mathrm{Cl}-3.93$ to $8.55 \otimes \mathrm{P}=0.47$ ) (Figure 3B). Therefore, the use of albumin and HES as priming fluid for $\mathrm{CPB}$ in cardiac surgery had a similar effect on ventilation time. (Figure 3B)

2.3.3 The length of hospital stay. Two RCTs reported the length of hospital stay. Two was statistical heterogeneity among the studies $\left(P=0.48 ; I^{2}=0 \%\right)$, and the random effect model was selected for analysis. The results showed no significant difference between the HES group and the albumin group $(\mathrm{MD}=-0.31 ; 95 \% \mathrm{Cl}:-2.00$ to $1.37 ; \mathrm{P}=0.71)$ (Figure $3 \mathrm{C}$ ).

2.3.4 Crystal volume. Three RCTs reported crystal volume. There was no statistical heterogeneity among the studies $\left(P=0.60 ; I^{2}=0 \%\right)$, and the random effect model was selected for analysis. The results showed no significant difference between the HES group and the albumin group (MD $=0.26 ; 95 \% \mathrm{Cl}:-0.09$ to $0.61 ; P=0.15)$ (Figure 3D).

2.3.5 Fresh frozen plasma. Three RCTs reported fresh frozen plasma. There was statistical heterogeneity among the studies $\left(P=\left.0.66 \mathrm{\otimes l}\right|^{2}=0 \%\right)$, and the random effect model was selected for analysis. The results showed no statistical difference between the HES group and the albumin group (SMD $=0.25 \otimes 95 \% \mathrm{Cl} \backslash-0.08$ to $0.59 \rrbracket \mathrm{P}=0.14$ ) (Figure 3E).

2.3.6 Platelet input. Two RCTs reports platelet input. There was no statistical heterogeneity among the studies $\left(P=\left.0.75 \nabla\right|^{2}=0 \%\right)$, and the random effect model was selected for analysis. The results showed no statistical difference between the HES group and the albumin group (MD $=-0.17 ; 95 \% \mathrm{Cl} \backslash-0.59$ to $0.26 \rrbracket p=$ 0.45) (Figure 3F).

2.3.7 Blood loss. Five RCTs reports blood loss. There was no statistical heterogeneity among the studies $\left(P=\left.0.23 \otimes\right|^{2}=29 \%\right)$, and the random effect model was selected for analysis. The results showed no statistical difference between the HES group and the albumin group ( $M D=0.31 ; 95 \%$ Cl囚-0.01 to $0.63 \rrbracket p=$ 0.06) (Figure 4A).

2.3.8 Platelet count. Five RCTs reported platelet count. There was no statistical heterogeneity among the studies $\left(P=0.18 ; I^{2}=37 \%\right)$, and the random effect model was selected for analysis. The results showed 
no statistical difference between the HES group and the albumin group (MD $=-0.21 ; 95 \%$ cl: -0.54 to $0.11 ; p$ $=0.20$ ) (Figure 4B).

2.3.9 Hemoglobin value. Five RCTs reported hemoglobin value. There was no statistical heterogeneity among the studies $\left(P=0.96 ; I^{2}=0 \%\right)$, and the random effect model was selected for analysis. The results showed no statistical difference between the HES group and the albumin group (MD $=0.1 ; 95 \% \mathrm{Cl}:-0.15$ to $0.36 ; \mathrm{P}=0.42)$ (Figure 4C).

2.3.10 Fibrin. Three RCTs reported fibrin. There was no statistical heterogeneity among the studies $(P=$ $0.91 ; 1^{2}=0 \%$ ), and the random effect model was selected for analysis. The results showed no statistical difference between the HES group and the albumin group ( $\mathrm{MD}=0.12 ; 95 \% \mathrm{Cl}:-0.19$ to $0.44 ; \mathrm{P}=0.45$ ) (Figure 4D).

2.3.11 APTT. Four RCTs reported APTT. There was no statistical heterogeneity among the studies $(\mathrm{P}=$ $\left.0.83 ; I^{2}=0 \%\right)$, and the random effect model was selected for analysis. The results showed no statistical difference between the HES group and the albumin group ( $M D=1.13 ; 95 \% \mathrm{Cl}:-2.06$ to $4.32 ; \mathrm{P}=0.49$ ) (Figure 4E).

2.3.12 PT. Three RCTs reported PT. There was no statistical heterogeneity among the studies $\left(P=0.10 ; I^{2}\right.$ $=0 \%$ ), and the random effect model was selected for analysis. The results showed no statistical difference between the HES group and the albumin group (MD $=0.10 ; 95 \% \mathrm{Cl}:-0.21$ to $0.40 ; \mathrm{P}=0.52$ ) (Figure 4F).

2.3.13 Urea. Two RCTs reported hemoglobin urea. There was no statistical heterogeneity among the studies $\left(P=0.58 ; I^{2}=0 \%\right)$, and the random effect model was selected for analysis. The results showed statistical difference between the HES group and the albumin group ( $\mathrm{MD}=-0.46 ; 95 \% \mathrm{Cl}:-0.81$ to $-0.11 ; \mathrm{P}=$ 0.01) (Figure 5A).

2.3.14 Creatinine. Three RCTs reported creatinine. There was no statistical heterogeneity among the studies $\left(P=0.09 ; I^{2}=51 \%\right)$, and the random effect model was selected for analysis. The results showed no statistical difference between the HES group and the albumin group (MD $=0.09 ; 95 \% \mathrm{Cl}:-0.32$ to $0.50 ; \mathrm{P}$ $=0.66$ ) (Figure 5B).

2.3.15 Urine volume. Five RCTs reported urine volume. There was no statistical heterogeneity among the studies $\left(P=0.14 ; I^{2}=43 \%\right)$, and the random effect model was selected for analysis. The results showed no statistical difference between the HES group and the albumin group (MD $=0.11 ; 95 \% \mathrm{Cl}:-0.26$ to $0.48 ; \mathrm{P}$ $=0.55)$ (Figure 5C).

\section{Discussion}

The use of HES in priming solution for CPB is still controversial. This meta-analysis included 9 RCTs that met the inclusion criteria to compare the impact of albumin and HES on the prognosis of patients. The 
results showed that compared with albumin, HES group had no statistical difference in the length of ICU stay, ventilator time, the length of hospital stay, crystal volume, fresh frozen plasma, platelet input, blood loss, blood platelet count. hemoglobin value, fibrin, APTT, PT, creatinine and urine volume, while HES group had lower urea than the control group.

The effects of HES on renal function were reported in the included studies, but the renal function test indexes were different, including blood creatinine, glomerular filtration rate, urine volume, urea, renal replacement therapy and other indexes. Because urea, blood creatinine and urine volume were common indexes reported in previous studies, we chose urea, blood creatinine and urine volume for analysis. Previous basic research and clinical trials have shown that HES has potential nephrotoxicity. A study found that HES was an independent risk factor for acute kidney injury after cardiac surgery [27]. However, other studies suggested that HES as priming fluid for CPB had no side effect on renal function ${ }^{[28]}$. Our results showed that HES had no different effects on serum creatinine and urine volume compared to albumin. The inconsistent results may be due to the molecular weight of HES. In their study they used macromolecular HES ${ }^{[29]}$. As the molecular weight of HES decreases, its effect on renal function becomes less. These data suggest that low molecular HES is safe for priming solution during CPB. But HES group had lower urea than the control group,may be the sample size included in this meta-analysis is relatively small.

HES may change the coagulation function in vivo and in vitro by prolonging the coagulation time, reducing the intensity of blood clots, and increasing blood loss of patients ${ }^{[30-31]}$. However, this metaanalysis found that HES had no different effect on fibrinogen value, platelet input, platelet count, APTT, PT and did not increase blood loss compared with albumin. It may be related to the new generation HES130/0.4 used in the most of studies enrolled in this meta-analysis. It was reported that the third generation HES130/0.4 did not increase blood loss ${ }^{[32]}$, because its molar replacement ratio was less than 0.5 and it was a rapidly degradable HES solution ${ }^{[33]}$. However, the sample size included in this metaanalysis is relatively small, and our conclusion needs to be confirmed by large-sample RCT study.

There was no difference between HES group and albumin group in the amount of liquid required during the operation, indicating that the volume expansion effect of HES was not different from that of albumin. However, large sample RCT studies are needed to confirm these results. Our results also found that HES group had no significant difference in the length of ICU stay and ventilation time compared with albumin group, indicating that HES treatment could not shorten the hospitalization time of patients. Since our data were estimated from the original data, our conclusion remains to be confirmed.

This meta-analysis is designed and implemented according to the requirements of Cochranne Collaboration Network. We strictly followed the inclusion criteria and exclusion criteria. Two independent authors chose articles, collected data and evaluated bias risks. Although this meta-analysis tried to use high-quality studies such as RCTs, we cannot completely eliminate the confounding and bias in independent studies, which inevitably lead to certain bias in the results. For example, some studies did not use blind methods, some studies did not report the hidden schemes and the generation of random 
sequences in detail, and some articles cannot trace other bias sources. In addition, only English literatures were included in this study, which may have publication bias. Moreover, the dosage of HES need to be considered, because the dosage used in different studies was different. In addition, the sample size of some studies was small. More RCTs with large samples and multiple centers are needed to confirm our conclusion.

Taken together, HES had no obvious side effects on renal function, coagulation function and did not prolong the length of ICU stay and ventilation time of patients. These results indicate that HES may be safe to be used as priming fluid for CPB. Even with some problems such as insufficient samples, different follow-up time and different dosage of HES, we think that the evidence is credible and the quality grade is judged as medium quality because all the included studies are RCTs, most of the studies used the random grouping and concealment methods, reported complete outcome indicators, had little heterogeneity among the experiments, and had consistent conclusions for all indicators.

\section{Conclusion}

This meta-analysis provides evidence that HES as priming fluid for CPB in cardiac surgery will not damage renal function, coagulation function or increase bleeding volume and intraoperative infusion volume as well as the length of ICU stay and ventilation time of patients, compared with albumin.

\section{Declarations}

\section{Author Contributions}

Xuming Mo囚Zhaocong Yang conceived and designed the study. Mingtang Ye edited the manuscript text and performed the statistical analyses. Xiaodong Zang $\bowtie$ Peicheng Ding analyzed and interpreted the data. Ruonan Wang collected data. Feng Chen, Jirong Qi prepared tables and figures. All authors read and approved the final version of the manuscript.

\section{Conflicts of Interest}

The authors declare that they have no competing interests.

\section{Ethics Approval and consent to participate}

Not applicable

\section{Consent for Publication}

Not applicable

\section{Availability of supporting data}

Not applicable 


\section{Funding}

This work was supported by funding from the National Natural Science Foundation of China (81970265, 81900281)

\section{Acknowledgements}

First and foremost, I would like to avail myself of the opportunity to express my gratitude to Xuming Mo, my tutor, who has taken his precious time off from his tight schedule, reading my thesis carefully and offering me constant encouragement, valuable suggestions and enlightening instructions, which contribute to the completion of my thesis.

I would also like to acknowledge my indebtedness to Xiaodong Zang, Peicheng Ding, Ruonan Wang , Feng Chen , Jirong Qi , Zhaocong Yang and many others who have contributed their time, thoughts, skills and encouragement to this thesis. I am also grateful to all the classmates and friends who have given me generous support and helpful advice in the past few years. Finally, I wish to devote this paper to my beloved family, who have given me life and love.

\section{References}

1. Moret E, Jacob MW, Ranucci M, Schramko AA. Albumin-Beyond Fluid Replacement in Cardiopulmonary Bypass Surgery: Why, How, and When. Semin Cardiothorac Vasc Anesth. 2014. 18(3): 252-9.

2. Chores JB, Holt DW. Colloid Oncotic Pressure, Monitoring its Effects in Cardiac Surgery. J Extra Corpor Technol. 2017. 49(4): 249-256.

3. Himpe D. Colloids versus crystalloids as priming solutions for cardiopulmonary bypass: a metaanalysis of prospective, randomised clinical trials. Acta Anaesthesiol Belg. 2003. 54(3): 207-15.

4. Engelman DT, Adams DH, Byrne JG, et al. Impact of body mass index and albumin on morbidity and mortality after cardiac surgery. J Thorac Cardiovasc Surg. 1999. 118(5): 866-73.

5. Fritz HG, Brandes $\mathrm{H}$, Bredle DL, et al. Post-operative hypoalbuminaemia and procalcitonin elevation for prediction of outcome in cardiopulmonary bypass surgery. Acta Anaesthesiol Scand. 2003. 47(10): 1276-83.

6. Sedrakyan A, Gondek K, Paltiel D, Elefteriades JA. Volume expansion with albumin decreases mortality after coronary artery bypass graft surgery. Chest. 2003. 123(6): 1853-7.

7. Onorati F, Santarpino G, Renzulli A, et al. Does priming implementation with low-dose albumin reduce postoperative bleeding following cardiopulmonary bypass. Int J Artif Organs. 2003. 26(3): 211-6.

8. Tiryakioğlu O, Yildiz G, Vural H, Goncu T, Ozyazicioglu A, Yavuz S. Hydroxyethyl starch versus Ringer solution in cardiopulmonary bypass prime solutions (a randomized controlled trial). J Cardiothorac Surg. 2008. 3: 45. 
9. Kuitunen AH, Hynynen MJ, Vahtera E, Salmenperä MT. Hydroxyethyl starch as a priming solution for cardiopulmonary bypass impairs hemostasis after cardiac surgery. Anesth Analg. 2004. 98(2): 291-7, table of contents.

10. de Jonge E, Levi M. Effects of different plasma substitutes on blood coagulation: a comparative review. Crit Care Med. 2001. 29(6): 1261-7.

11. Schortgen F, Lacherade JC, Bruneel F, et al. Effects of hydroxyethylstarch and gelatin on renal function in severe sepsis: a multicentre randomised study. Lancet. 2001. 357(9260): 911-6.

12. Russell JA, Navickis RJ, Wilkes MM. Albumin versus crystalloid for pump priming in cardiac surgery: meta-analysis of controlled trials. J Cardiothorac Vasc Anesth. 2004. 18(4): 429-37.

13. Myburgh JA, Finfer S, Bellomo R, et al. Hydroxyethyl starch or saline for fluid resuscitation in intensive care. N Engl J Med. 2012. 367(20): 1901-11.

14. No Differences in Renal Function between Balanced 6\% Hydroxyethyl Starch (130/0.4) and 5\% Albumin for Volume Replacement Therapy in Patients Undergoing Cystectomy: A Randomized Controlled Trial: Erratum. Anesthesiology. 2018. 128(4): 863.

15. Higgins JP, Altman DG, Gøtzsche PC, et al. The Cochrane Collaboration's tool for assessing risk of bias in randomised trials. BMJ. 2011. 343: d5928.

16. Hozo SP, Djulbegovic B, Hozo I. Estimating the mean and variance from the median, range, and the size of a sample. BMC Med Res Methodol. 2005. 5: 13.

17. Higgins JP, Thompson SG. Quantifying heterogeneity in a meta-analysis. Stat Med. 2002. 21(11): 1539-58.

18. Miao N, Yang J, Du Z, et al. Comparison of low molecular weight hydroxyethyl starch and human albumin as priming solutions in children undergoing cardiac surgery. Perfusion. 2014. 29(5): 462-8.

19. Patel J, Prajapati M, Solanki A, Pandya H. Comparison of Albumin, Hydroxyethyl Starch and Ringer Lactate Solution as Priming Fluid for Cardiopulmonary Bypass in Paediatric Cardiac Surgery. J Clin Diagn Res. 2016. 10(6): UC01-4.

20. Saunders CR, Carlisle L, Bick RL. Hydroxyethyl starch versus albumin in cardiopulmonary bypass prime solutions. Ann Thorac Surg. 1983. 36(5): 532-9.

21. Van der Linden P, De Villé A, Hofer A, Heschl M, Gombotz H. Six percent hydroxyethyl starch 130/0.4 (Voluven ${ }^{\circledR}$ ) versus $5 \%$ human serum albumin for volume replacement therapy during elective openheart surgery in pediatric patients. Anesthesiology. 2013. 119(6): 1296-309.

22. Kuitunen AH, Hynynen MJ, Vahtera E, Salmenperä MT. Hydroxyethyl starch as a priming solution for cardiopulmonary bypass impairs hemostasis after cardiac surgery. Anesth Analg. 2004. 98(2): 291-7, table of contents.

23. Cho JE, Shim JK, Song JW, Lee HW, Kim DH, Kwak YL. Effect of 6\% hydroxyethyl starch $130 / 0.4$ as a priming solution on coagulation and inflammation following complex heart surgery. Yonsei Med J. 2014. 55(3): 625-34. 
24. Palanzo DA, Parr GV, Bull AP, Williams DR, O'Neill MJ, Waldhausen JA. Hetastarch as a prime for cardiopulmonary bypass. Ann Thorac Surg. 1982. 34(6): 680-3.

25. Hosseinzadeh Maleki M, Derakhshan P, Rahmanian Sharifabad A, Amouzeshi A. Comparing the Effects of 5\% Albumin and 6\% Hydroxyethyl Starch 130/0.4 (Voluven) on Renal Function as Priming Solutions for Cardiopulmonary Bypass: A Randomized Double Blind Clinical Trial. Anesth Pain Med. 2016. 6(1): e30326.

26. Choi YS, Shim JK, Hong SW, Kim JC, Kwak YL. Comparing the effects of $5 \%$ albumin and $6 \%$ hydroxyethyl starch 130/0.4 on coagulation and inflammatory response when used as priming solutions for cardiopulmonary bypass. Minerva Anestesiol. 2010. 76(8): 584-91.

27. Rioux JP, Lessard M, De Bortoli B, et al. Pentastarch $10 \%$ (250 kDa/0.45) is an independent risk factor of acute kidney injury following cardiac surgery. Crit Care Med. 2009. 37(4): 1293-8.

28. Akkucuk FG, Kanbak M, Ayhan B, Celebioglu B, Aypar U. The effect of HES (130/0.4) usage as the priming solution on renal function in children undergoing cardiac surgery. Ren Fail. 2013. 35(2): 2105 .

29. Oh HW, Lee JH, Kim HC, et al. The effect of $6 \%$ hydroxyethyl starch (130/0.4) on acute kidney injury in paediatric cardiac surgery: a prospective, randomised trial. Anaesthesia. 2018. 73(2): 205-215.

30. Niemi TT, Kuitunen AH. Hydroxyethyl starch impairs in vitro coagulation. Acta Anaesthesiol Scand. 1998. 42(9): 1104-9.

31. Schramko AA, Suojaranta-Ylinen RT, Kuitunen AH, Kukkonen SI, Niemi TT. Rapidly degradable hydroxyethyl starch solutions impair blood coagulation after cardiac surgery: a prospective randomized trial. Anesth Analg. 2009. 108(1): 30-6.

32. Vogt $\mathrm{NH}$, Bothner $\mathrm{U}$, Lerch $\mathrm{G}$, Lindner $\mathrm{KH}$, Georgieff $\mathrm{M}$. Large-dose administration of $6 \%$ hydroxyethyl starch 200/0.5 total hip arthroplasty: plasma homeostasis, hemostasis, and renal function compared to use of 5\% human albumin. Anesth Analg. 1996. 83(2): 262-8.

33. Felfernig M, Franz A, Bräunlich P, Fohringer C, Kozek-Langenecker SA. The effects of hydroxyethyl starch solutions on thromboelastography in preoperative male patients. Acta Anaesthesiol Scand. 2003. 47(1): 70-3.

\section{Figures}




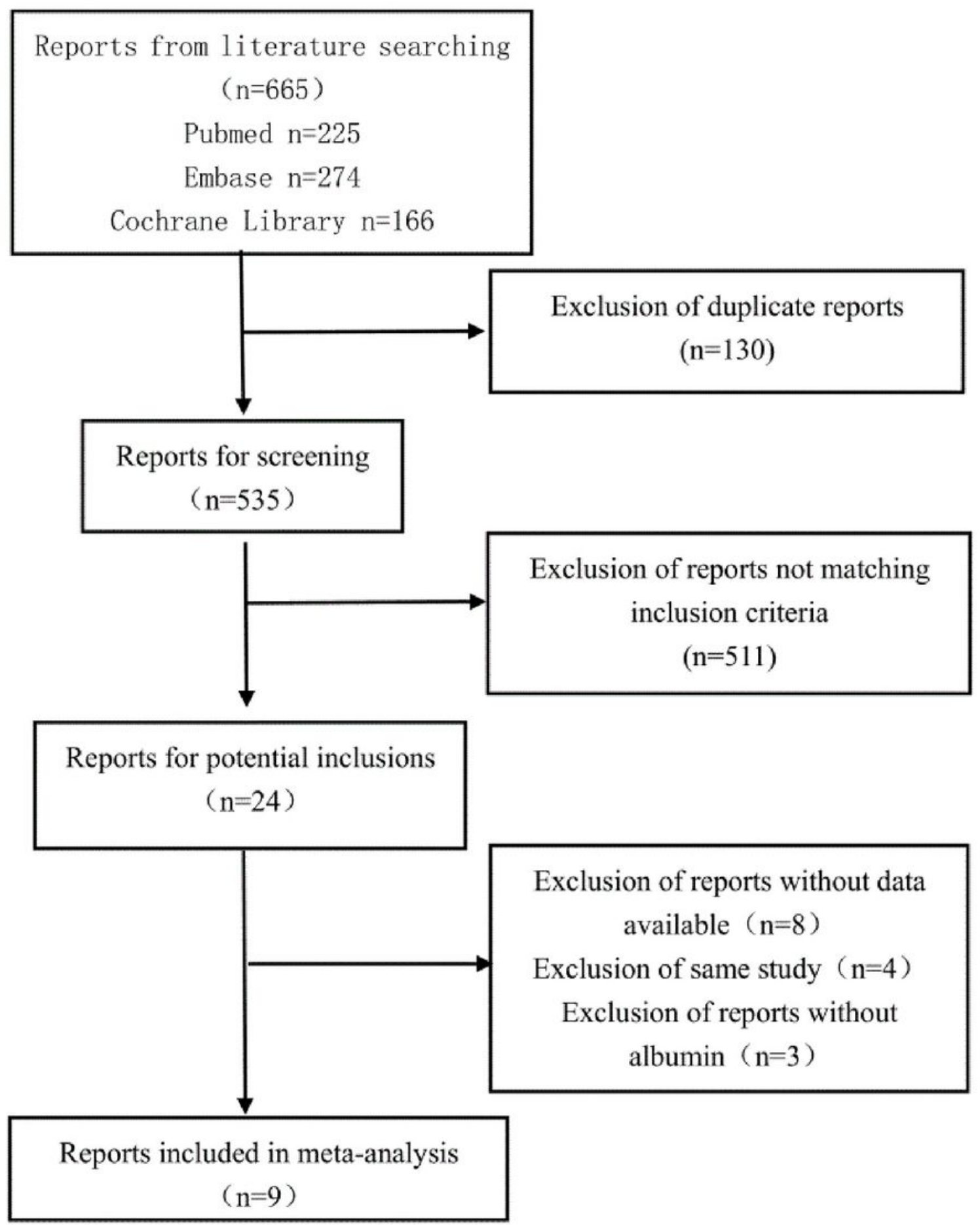

Figure 1

The flow chart of the literature search. 
Random sequence generation (selection bias)

Allocation concealment (selection bias)

Blinding of participants and personnel (performance bias)

Blinding of outcome assessment (detection bias)

Incomplete outcome data (attrition bias)

Selective reporting (reporting bias)

Other bias
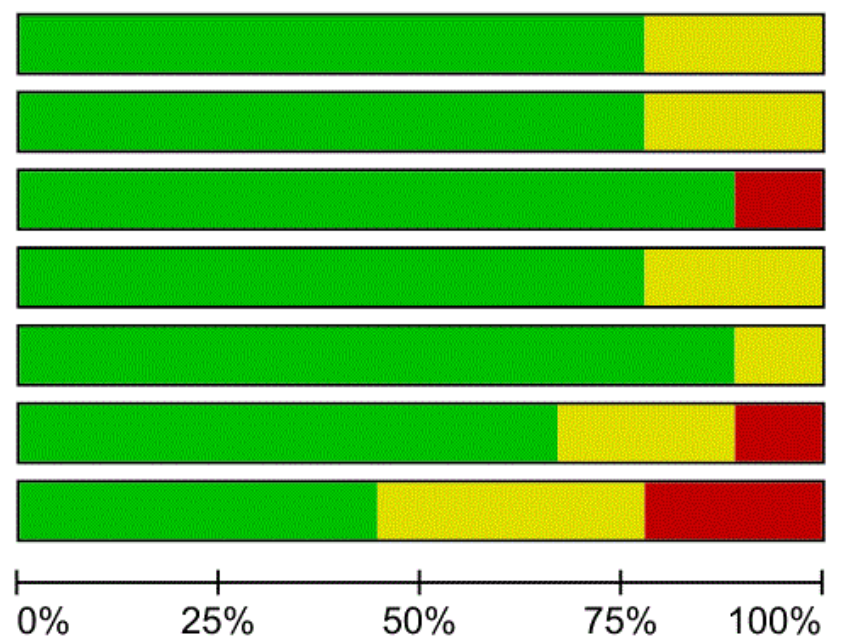

Low risk of bias

Unclear risk of bias

High risk of bias

Figure 2

Quality of the included studies 
A

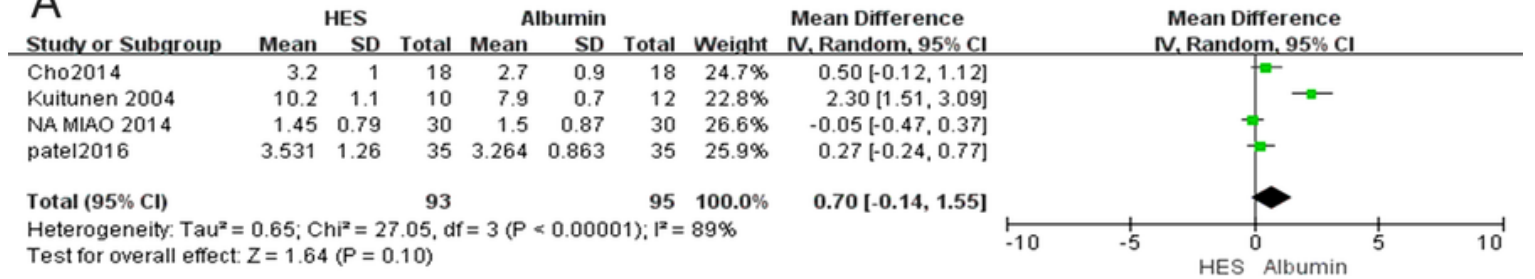

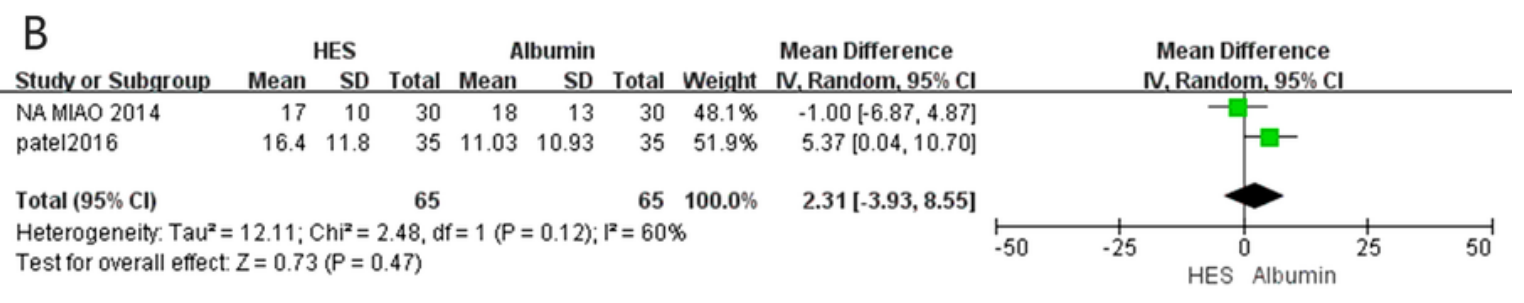

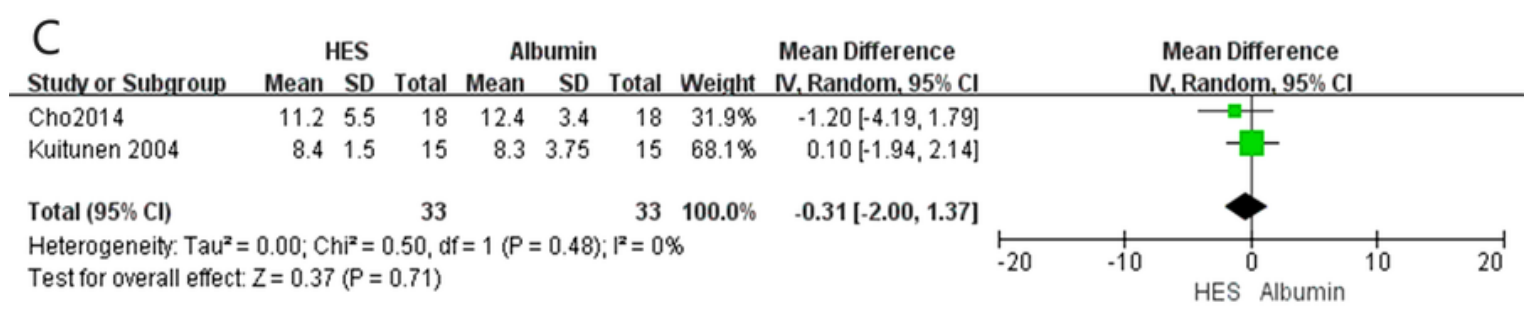

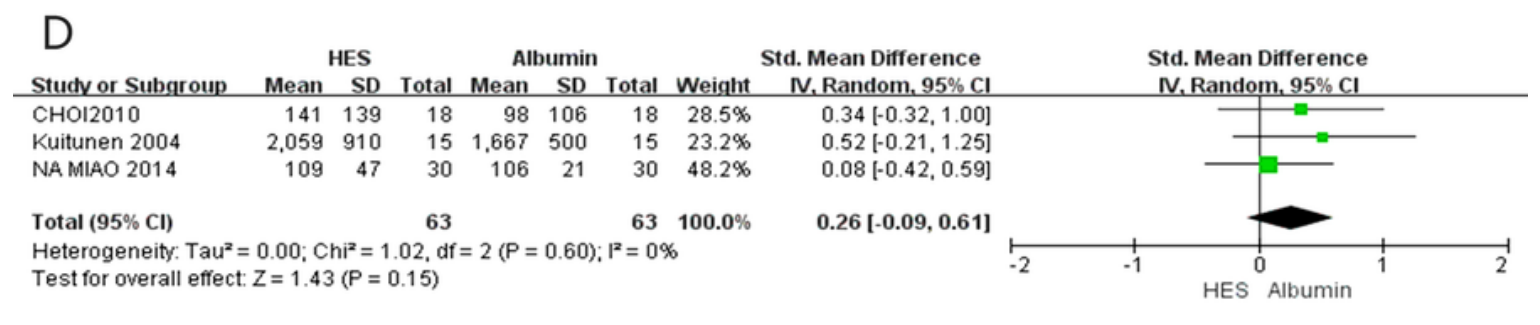

\footnotetext{
$\mathrm{E}$
}

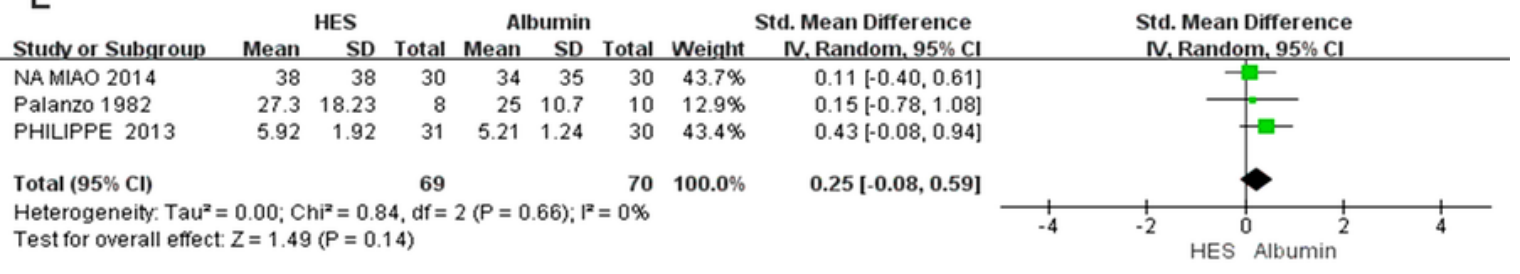

\section{$\mathrm{F}$}

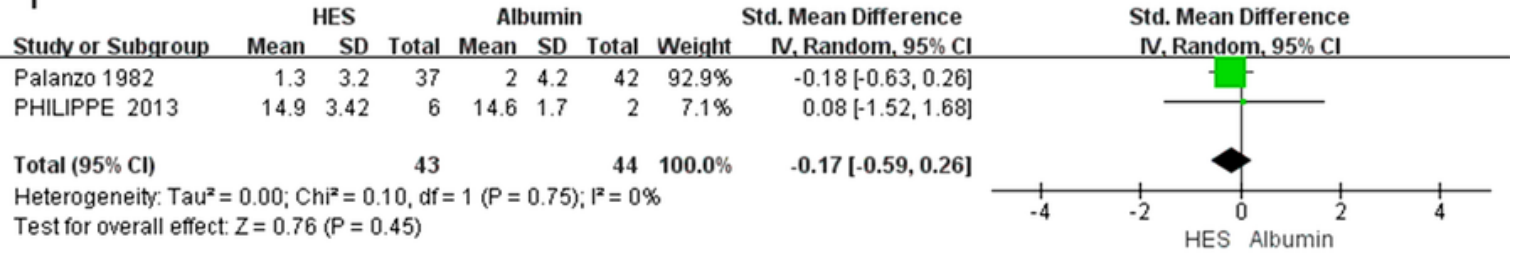

\section{Figure 3}

Forest plot of the meta-analysis (A) Length of ICU stay (B) Ventilation time. (C) Length of hospital stay. (D) Crystal volume. (E) Fresh frozen plasma. (F) Platelet input. 
A

\begin{tabular}{|c|c|c|c|c|c|c|c|}
\hline \multirow[b]{2}{*}{ Stucty or Subgroup } & \multicolumn{3}{|c|}{ HES } & \multicolumn{3}{|c|}{ Albumin } & \multirow{2}{*}{ Weight } \\
\hline & Mean & SD & Total & Mean & SD & Total & \\
\hline Cho2014 & 495 & 202.5 & 18 & 430 & 101.3 & 18 & $17.6 \%$ \\
\hline $\mathrm{CHOI} 2010$ & 103 & 143 & 18 & 107 & 45 & 18 & $17.8 \%$ \\
\hline Kuitunen 2004 & 1.359 & 370 & 15 & 1,098 & 377.5 & 15 & $14.8 \%$ \\
\hline Mahmood2015 & 1.121 & 584.58 & 30 & 799.84 & 382.75 & 30 & $24.5 \%$ \\
\hline PHILIPPE 2013 & 14.5 & 16 & 31 & 15.4 & 16.95 & 29 & $25.3 \%$ \\
\hline 6 Cl) & & & 112 & & & 110 & $100.0 \%$ \\
\hline
\end{tabular}

Std. Mean Difference

Std. Mean Difference

IV. Random, $95 \% \mathrm{CI}$

$0.40[-0.26,1.06]$

$-0.04[-0.69,0.62]$

$0.64[0.12,1.16]$

$-0.05[-0.56,0.45]$

$0.31[-0.01,0.63]$

Test for overall effect: $Z=1.88(P=0.06)$

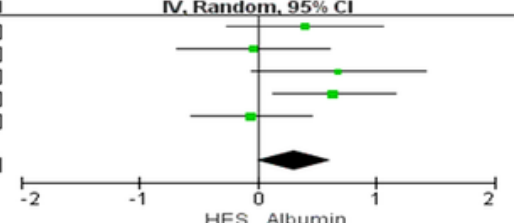

B

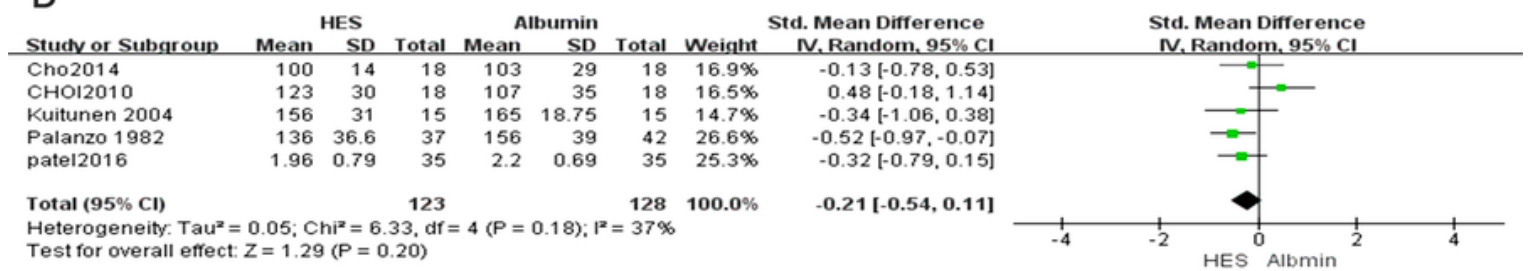

C
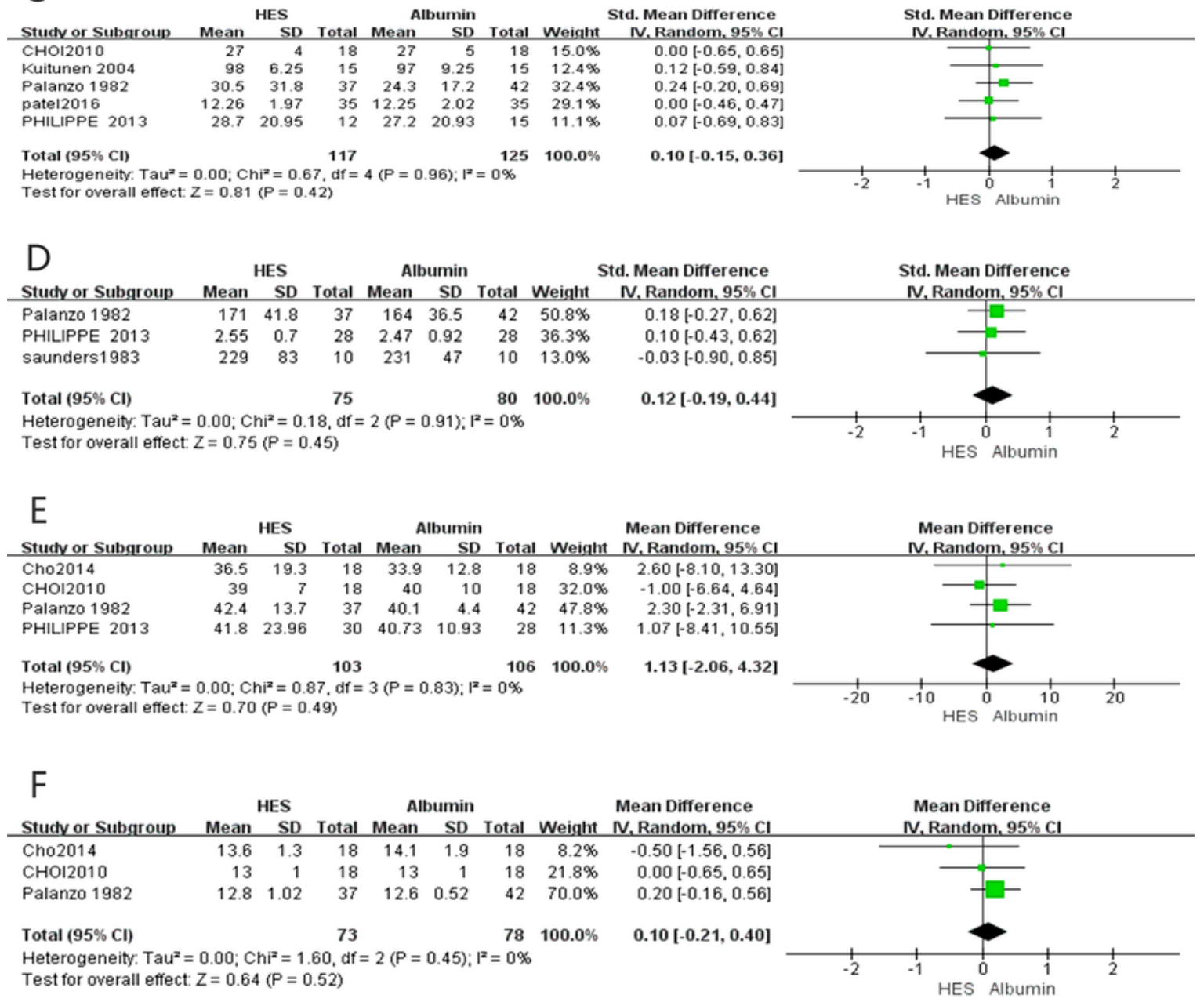

Figure 4

Forest plot of the meta-analysis (A) Blood loss, (B)Blood platelet count. (C)Hemoglobin value, (D)Fibrin, (E) APTT, (F)PT 
A

HES

Albumin

Std. Mean Difference IV. Random, 95\% Cl

$\begin{array}{lrrrrrrr} & & & & & \\ \text { patel2016 } & 24.88 & 8.93 & 35 & 29.28 & 6.63 & 35 & 53.8 \% \\ \text { PHILIPPE 2013 } & 5.91 & 2.13 & 31 & 6.66 & 2.02 & 28 & 46.2 \%\end{array}$

PHILIPPE 2013

\section{6}

$63100.0 \%$

Heterogeneity: Tau $^{2}=0.00 ; \mathrm{Chi}^{2}=0.30, \mathrm{df}=1(\mathrm{P}=0.58) ; \mathrm{I}^{2}=0 \%$

Test for overall effect: $Z=2.58(P=0.010)$

$-0.55[-1.03,-0.08]$

$-0.36[-0.87,0.16]$

$-0.46[-0.81,-0.11]$

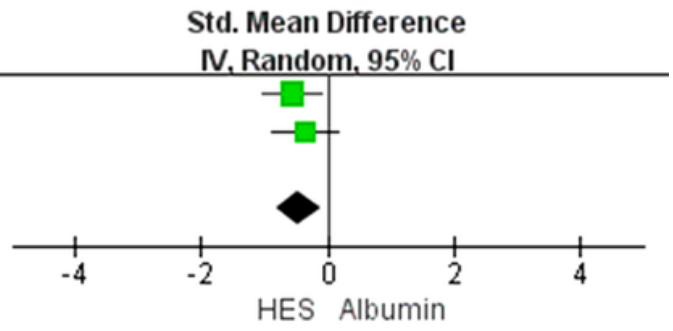

B

\begin{tabular}{|c|c|c|c|c|c|c|c|}
\hline \multirow[b]{2}{*}{ Study or Subgroup } & \multicolumn{2}{|r|}{ HES } & \multicolumn{5}{|c|}{ Albumin } \\
\hline & Mean & SD & Total & Mean & SD & Total & Weight \\
\hline Mahmood2015 & 1.01 & 0.16 & 30 & 1.03 & 0.2 & 30 & $32.8 \%$ \\
\hline patel2016 & 0.49 & 0.104 & 35 & 0.43 & 0.135 & 35 & $34.8 \%$ \\
\hline PHILIPPE 2013 & 37.5 & 16.7 & 31 & 40.4 & 25.5 & 28 & $32.4 \%$ \\
\hline Total $(95 \% \mathrm{Cl})$ & & & 96 & & & 93 & $100.0 \%$ \\
\hline
\end{tabular}

Std. Mean Difference

Std. Mean Difference

IV, Random, 95\% Cl

$-0.11[-0.62,0.40]$

$0.49[0.02,0.97]$

$-0.13[-0.65,0.38]$

$0.09[-0.32,0.50]$

Test for overall effect: $Z=0.44(P=0.66)$

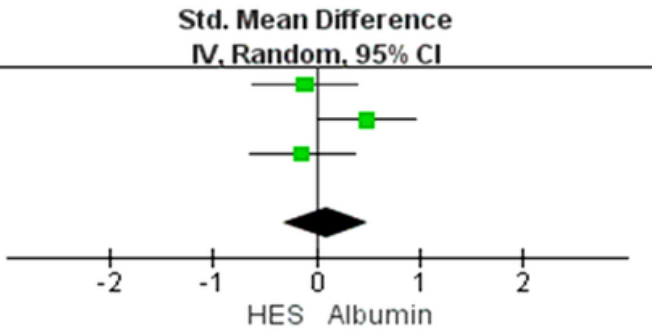

C

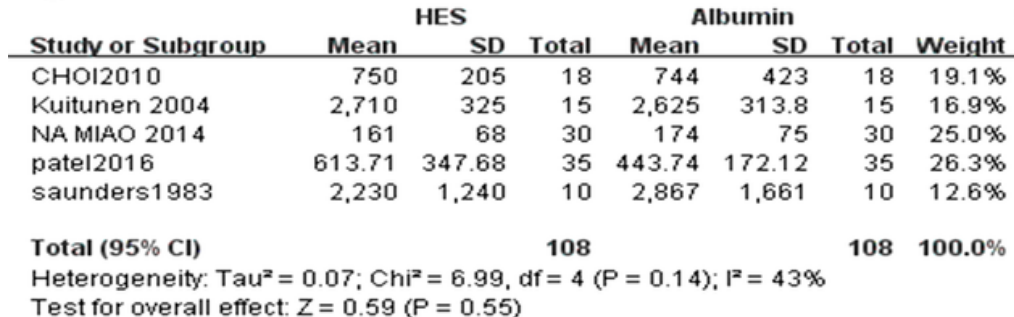

Std. Mean Difference Std. Mean Difference

IV. Random, 95\% Cl

$0.02[-0.64,0.67]$

$0.26[-0.46,0.98]$

$-0.18[-0.69,0.33]$

$0.61[0.13,1.09]$

$-0.42[-1.30,0.47]$

$0.11[-0.26,0.48]$

IV. Random, $95 \% \mathrm{Cl}$

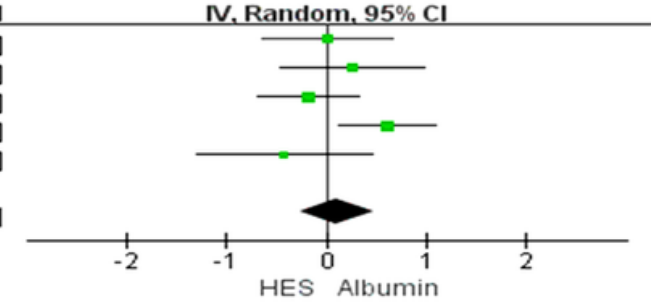

\section{Figure 5}

(A) Urea, (B) Creatinine,(C) Urine volume.

\section{Supplementary Files}

This is a list of supplementary files associated with this preprint. Click to download.

- SupplementaryFigureS1.tif

- Tables1.docx 